\title{
Educational technology for inclusion: Design of an educational software for individuals with autism spectrum disorders
}

\author{
Di Tore Stefano ${ }^{\mathrm{a}}$, Sibilio Maurizio ${ }^{\mathrm{b}}$ \\ ${ }^{a}$ University of Salerno, Italy, sditore@unisa.it, 0000-0003-1796-6744 \\ ${ }^{b}$ University of Salerno, Italy,msibilio@unisa.it,0000-0003-1322-7776
}

\begin{abstract}
The study illustrates the design, prototyping and production stages of an educational software aimed at promoting the development of social skills in autistic pupils attending the Italian primary school. The educational design of the proposed activities within the software was created on the basis of the theory of simplexity, while the design of the forms of interaction of the activities was constructed on the basis of the tasks proposed in the educational programme for autistic individuals by Patricia Howlin. The research project aims to achieve two objectives: creating an educational freeware software designed to foster the development of social skills in autistic pupils attending Italian primary schools; assessing if and to what extent the introduction of a technological variable can determine changes in terms of teaching effectiveness in Howlin's programme.
\end{abstract}

Keywords: Didactics, Technology, Simplexity, Inclusion, Autism.

\section{Introduction}

Autism can be defined as a severe and chronic developmental disorder characterised by deficits in social and communicative behaviour and by a limited interest in the environment, towards which a restricted, often stereotyped, number of initiatives are taken (Gallese, 2006).

There is wide acknowledgement in scientific literature ranging from psychology to neuroscience that most of the classic symptoms presented by people with autism spectrum disorders can be attributed to a deficit related to a particular cognitive skill referred to as 'mind reading' (Frith, 2010).

This skill refers to the ability to attribute a 'mind' to oneself and to others. In other words, humans spontaneously develop an intuitive understanding of the fact that other human beings have their own mental states and act on their basis (Colman, 2001).

The ability to 'mind read' or to 'mentalise' seems to be at the basis of important cognitive functions such as interacting differently when in contact with living organisms and inanimate objects (Baron-Cohen, 1997), attributing a meaning to interpersonal behaviour and communication (Grice, 1975), being able to deceive or cajole (Baron-Cohen, 1997) and so on.

There is a tendency, therefore, to consider 'mind reading' as the result of highly specialised cognitive mechanisms and as a complex skill that is part of the natural development of the individual. This also implies that this ability is acquired and used in a natural way and in most cases, unconsciously.

Bearing in mind the functions in which the process of mentalising is involved, it is clear that it represents a milestone in the development of an individual's social skills. However, this does not always happen, as in the case of people with autism spectrum disorders who show deficits related to communication and social behaviour. In a nutshell, therefore, the hypothesis presented in the theory of mind is, that autism arises 'from a lack of modules of the theory of mind specifically selected during development' (Gallese, 2006; Baron- Cohen, 1985; Baron-Cohen, 1988, 1995). An array of experimental studies have provided considerable empirical evidence of the hypothesis that the combination of symptoms related to autism can be explained by hypothesising a deficit in the ability to mentalise, considered as a form of mind blindness (Baron-Cohen, 1997). Moreover, according to several recent studies, such a deficit in autistic subjects is accompanied by a greater ability to schematise (i.e. the ability to identify regularities inherent to a system or phenomenon). In fact, on average, individuals with autism spectrum disorders perform better on schematic/schematised 


\section{Educational technology for inclusion: Design of an educational software for individuals with autism spectrum disorders \\ Di Tore, Sibilio}

tests when compared to individuals with a typical development. The combination of the two elements (mind blindness and high capacity for schematisation) therefore seems to delineate a particular type of cognitive style among these individuals (Baron-Cohen, 2003), which as a consequence has significant implications on the choice of the teaching strategies used.

\section{Didactics and mind reading}

Attempts to assess and exploit the implications that the theory of mind presents from an educational perspective have thrown varied conclusions. In particular, one of the educational programmes that seems to have been particularly effective in favouring the development of social skills in autistic individuals is the one designed and produced by the English psychologist Patricia Howlin, which was developed on the basis of the theory of mind (Hadwin, 2014). The underpinning assumption of the programme is that the combination of symptoms demonstrated by individuals with autism spectrum disorders can be partly compensated by specific activities aimed at promoting the development of conscious alternative cognitive strategies in relation to the mentalising process. It must also be noted that recent studies have raised a number of criticisms of the 'theory of mind' by hypothesising that the combination of symptoms demonstrated by people with autism spectrum disorders may result from a failure to develop the skill of 'embodied simulation'.

Although it is not possible to provide a detailed explanation of the underlying theory and an exhaustive description of these studies in this article, it is functional for the purpose of the argument presented here to provide a brief overview of the results that these studies have led to, because of their significant educational implications. In brief, such studies ascribe the impossibility to create meta-representations of the minds of others and, therefore, to attribute to others moods, thoughts and beliefs, to a neural deficit of the mirror neuron systems. According to such hypothesis, these deficits prevent autistic individuals to experience, and as a result to 'simulate', first hand and in an unconscious way, what others experience, think, believe or feel (Gallese, 1998; Gallese, 2004), thus making it impossible for them to develop a spontaneous activity of 'mind reading'. In other words, these studies interpret the impossibility to mentalise as the effect of a deficiency of the mirror neuron systems and not as the effect of a lack of development of cognitive systems specialised in the process of mind reading. Furthermore, these studies have shown that even when individuals with autism spectrum disorders are able to recognise and imitate the emotions, they do it by using a completely different strategy, which activates completely different neural patterns than the one used by typically developing subjects (Grandin, 1995). Studies seem to show that the theorisation of the intentional world of the other is far from being the deficit at the basis. Instead, it is the only lifeline; the only strategy available when the most basic cognitive tools aimed at automatically sharing the implicit certainties, which provide meaning to other individuals' world are missing (Gallese, 2006). In other words, for such persons access to 'other people's world' is possible only through a theoretical and conscious cognitive reconstruction of this world. The studies mentioned, albeit from different positions with respect to Howlin's programme, seem to support its aims. In fact, regardless of the position held on the causes of autism spectrum disorders, both theories (the theory of mind and the theory of embodied simulation), seem to suggest, even by virtue of the aforementioned experimental results, that at present, one of the most effective ways to promote social inclusion of persons with autism spectrum disorders is to encourage them to develop alternative cognitive strategies aimed to 'read the minds' of others.

As a consequence, Howlin's programme appeared as a natural choice for the creation of an educational software. The programme, in fact, aims to help people with autism to develop an alternative, or 'vicarious' (Berthoz, 2015), cognitive strategy, which may enable them to circumvent mind blindness as far as possible. Howlin's programme is divided into three principal areas: emotions (Figure 1), beliefs and false beliefs (Figures 2 and 3), and pretend play. Every area is also composed of several stages, each of which has specific educational activities. All the activities proposed in the programme envisage the presence of the operator/educator and of the individual with autism. The role of the operator is to correct immediately the performance of the subject in case of error, On the other hand, if successful, the operator attempts to encourage a phase of reflection on the reply given to make the learner aware of the compensation strategy. Figures 1 and 2 illustrate some of the activities included in the programme. 

disorders

Di Tore, Sibilio

\section{LEVEL 2. RECOGNIZING EMOTION FROM SCHEMATIC DRAWINGS}

This is scored if the child is able to identify the correct face from four facial cartoons: happy, sad, angry, and afraid, in the same way as above

Figure 2.2 Schematic facial expressions of emotion (adapted from Hobson, 1989)

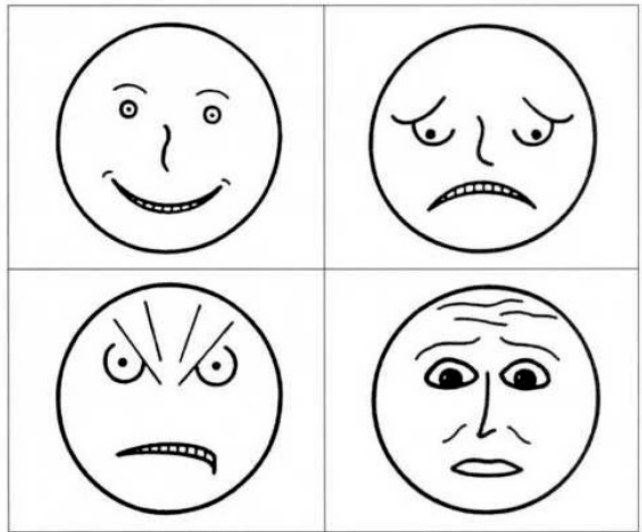

\section{leaching procedures}

Zhildren are asked to identify the four black-and-white cartoon facial expressions of emotion happy/sad/angry/afraid) in turn (randomized)

The teacher first places the set of pictures on the table and names the emotion shown in each one of hese. The child is then asked to match his or her faces to those placed by the teacher.

Fig. 1 Task on the recognition of emotions in schematic drawings.

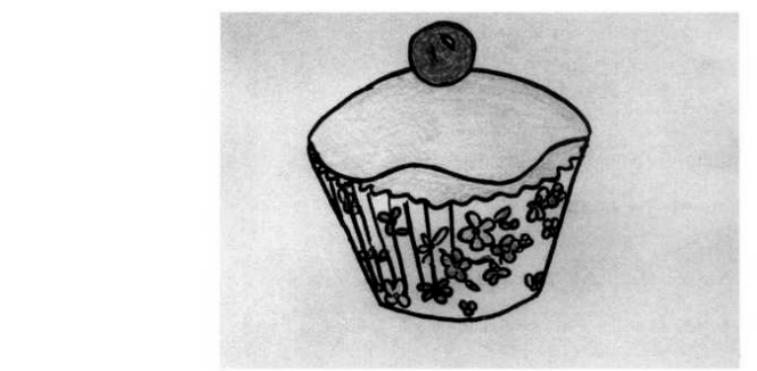

Side 1: Child's picture

Self-perception Question: What can you see?

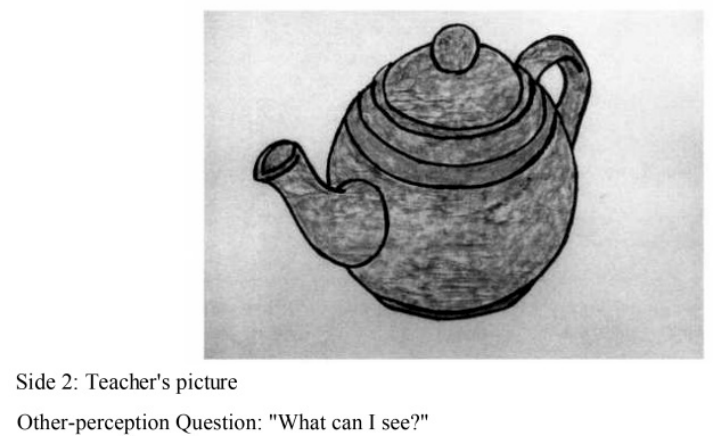

Fig. 2 The image presents part of a flashcard in Howlin's programme. The proposed activity on the card is on perspective taking. Two figures are printed, one on either side of the card. The operator holds the card in such a way that one side is facing him and the other faces the autistic child. The operator asks "what can you see?" and then, "what can I see?". 
Outcome 21A: Daniel's mummy asks him to ride to the shops.

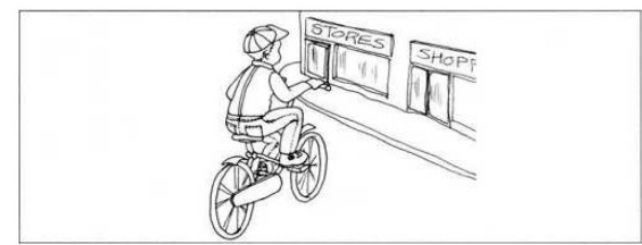

Desire Question: What does Daniel want?

prompt - look, this picture tells you what Daniel wants.

Emotion Question: How will Daniel feel when mummy asks him to ride to the shops?

prompt - will he feel happy/sad?

Justification Question: Why will he feel happy/sad?

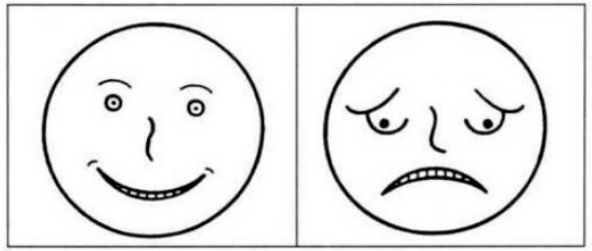

Teacher: Tell the child the desire of the story character and then describe the story outcome. Check that the child understands the desire of the story character before asking the child either to say how the person in the story feels, or to point to one of the emotion faces below.

\begin{abstract}
Fig. 3 The image presents part of a flashcard in Howlin's programme. The proposed activity on the card is on the understanding of emotions. The card features a cartoon that is a story. After a period using the story, the user is asked to indicate what feeling the protagonist will experience.
\end{abstract}

\title{
2. Didactics and schematisation capacity
}

Recent studies suggest that individuals with autism spectrum disorders generally show an above average capacity to schematise (Baron-Cohen, 2009), which refers to the ability of an individual to find a series of regular and repetitive patterns within a phenomenon or system.

From an educational point of view, this particular cognitive style seems to favour the learning of individuals with this condition when placed in contexts in which learning processes are guided by clear and highly schematised rules.

This particular cognitive style, characterised by mental blindness and a high capacity of schematisation, also allows to provide an explanation to one of the typical attitudes of this particular type of individuals: the ability to use tools and mechanical devices (Golan, 2010). Therefore, the natural inclination shown by autistic individuals in mathematics and in computer use would depend on whether these disciplines and these tools match their particular cognitive style since they are based on schematised and formalised languages.

On the basis of the above reflections, the use of software for instructional purposes specifically designed for this particular type of user can be considered an important educational opportunity. Starting from this assumption, the present study aims to create a digital and interactive version of Howlin's programme in order to maximise efficiency in the teaching-learning process to favour the acquisition of social skills in case of autistic children.

\section{Didactics and Simplexity}

To carry out the activities envisaged in Howlin's educational programme, both the presence of an operator and that of a learner are required. The operator is responsible for conveying a reflective process to encourage the mentalising process, previously outlined. During this process, the theory of simplexity appears to be an indispensable teaching guide in order to channel this reflection effectively. The choice of integrating Howlin's programme with simplex didactics is essentially based on an analogy on two levels:

1. The process of mentalisation itself may be considered as a simplex strategy;

2. Simplex didactics is based on a set of principles that guide the strategies that living organisms naturally put in place in the processes of adaptation/learning (Sibilio, 2014).

In relation to the first point, the ability to 'read the mind' can be considered as a simplex strategy because it is configured as a process consistent with the principles of simplex adaptation described by Alain Berthoz (Berthoz, 


\section{Educational technology for inclusion: Design of an educational software for individuals with autism spectrum disorders \\ Di Tore, Sibilio}

2011). In particular mentalisation allows to 'automate', at least in part, the process of understanding action and human behaviour, thus permitting the reduction of the computational burden of our 'actions' and navigate intuitively, quickly and flexibly, in social situations. Mentalising also has a role in the constitution of our umwelt as it allows the individual to create an ontology that divides the environment into two macro-categories: agents with a mind and inanimate objects. What derives from this distinction are profoundly different ways of interaction, as well as a perceptive bubble that it characterises the human being as a 'social animal'.

As regards the second point, if the theory of simplex didactics (Sibilio, 2014) essentially aims to make teachers aware of the principles that convey adaptation/learning strategies in order to use them effectively within their educational act (Rivoltella \& Rossi, 2010, Rossi, 2011) and if the process of mentalising is a simplex strategy of adaptation/learning, then simplex didactics may constitute a useful guide to convey reflection about the mechanisms involved in the process of mind reading effectively with the aim of favouring the development of a vicarious cognitive strategy (Rivoltella, 2014) for the development of social skills in individuals with autism.

\section{Software development}

At present, Howlin's programme is mainly composed of paper-based resources. Based on the elements explained in the preceding paragraphs, the development of an educational software based on the programme seems to be a significant didactic opportunity. In particular, the opportunities offered by similar software are concerned with:

- meeting the cognitive needs of people with autism spectrum disorders;

- facilitate the teacher's task by providing the material to conduct specific activities and reporting modules;

- provide the teacher with a guide for the delivery of its activities.

The software, which is currently being developed, is written C\# and uses Unity 3D as a framework. Currently, this software runs only on Windows. However, Unity 3D offers the possibility to create a cross-platform application that can also be run on different operating systems such as iOS and Android. Being an open-access software, this will also allow adaptability to other contexts and needs.

\section{Structure}

The software has been designed with a modular architecture and features an articulated structure composed of three areas, corresponding to the structure of Howlin's programme. Similarly, the tasks present in the software are based on the activities of the same programme and the proposed activities within the software are designed to be used by the autistic child in the presence of the teacher or the operator. The operator is accompanied in the use of the software by a guide based on simplex didactics and on studies carried out in relation to the theory of mind. So far the tasks realised are related to some of the sub-sections present in the first two parts of Howlin's programme.

In relation to the first area, 'emotion recognition' activities on the recognition of facial expressions in photographs and the recognition of emotions in schematic drawings have been created. In the first task (Figure 4), the software presents the picture of a face expressing an emotion (in the larger box on the left). The photos used in this task present faces expressing rage, happiness, sadness, disgust and surprise, in line with Howlin's programme and based on evidence provided in the literature (Gallese, 2006), which has shown that autistic children present problems to recognise these principal facial expressions. The objective of this task is that of guiding the user in creating mental schemes of facial features expressing an emotion. The user needs to choose which of the pictures (in the bottom bar) depicts a face expressing the same emotion. The software loads the images randomly from a folder, which is equipped with 125 photos by default, present in the system. This mechanism gives the operator the opportunity to customise the software (simply by inserting more images in the folder) and avoid sameness (showing the same series of photos each time the autistic child is presented with the task). This task proposes the activities related to the recognition of expressions in the first phase of Howlin's programme. 


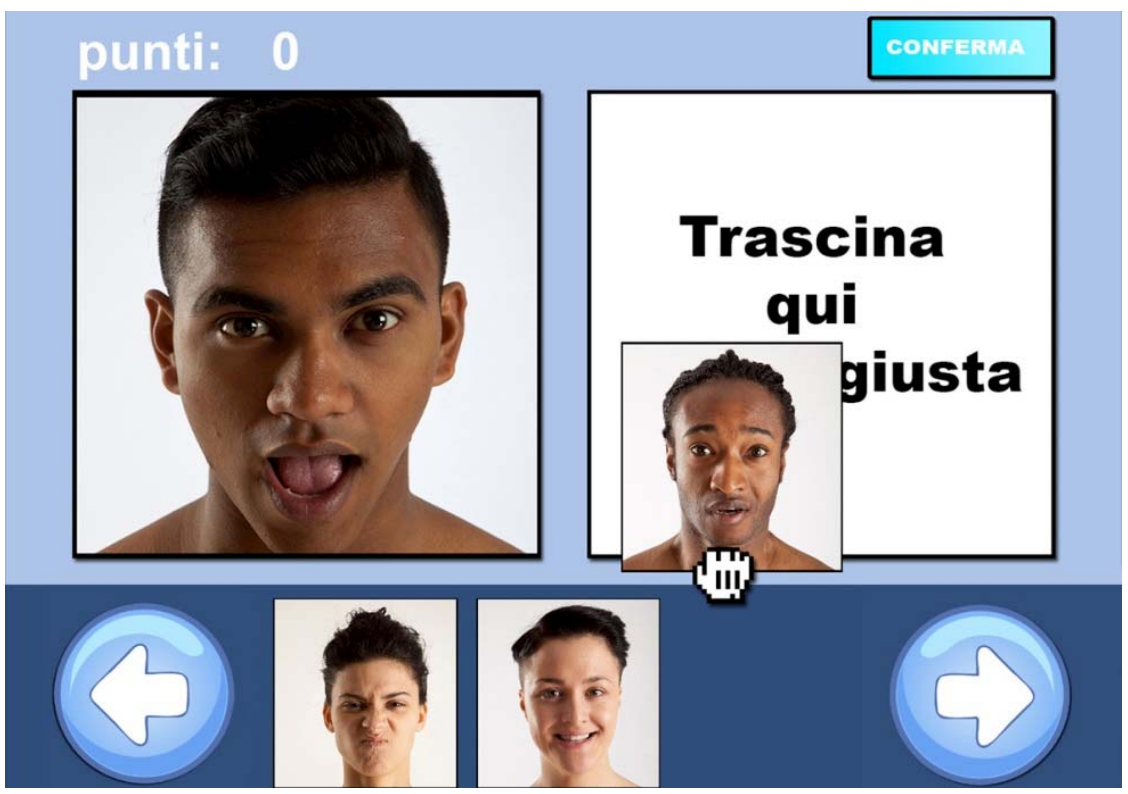

Fig. 4

Meanwhile, the second task proposed is the recognition of emotions in schematic drawings. These allow to accentuate the shape of some of the traits that characterise expressions (such as the position of the eyebrows, the shape of the mouth and eyes) and at the same time, eliminate elements that are not necessary for the recognition of an emotion (which were present in the first photos), for instance the shape of the face, skin colour, the nose and the ears. In this task, the user is asked to recognise emotions represented by figures (Figure 5). The proposed activity in the software requires the user to select the emoticon that expresses the emotion shown in the center pane. The uploading of files is random.

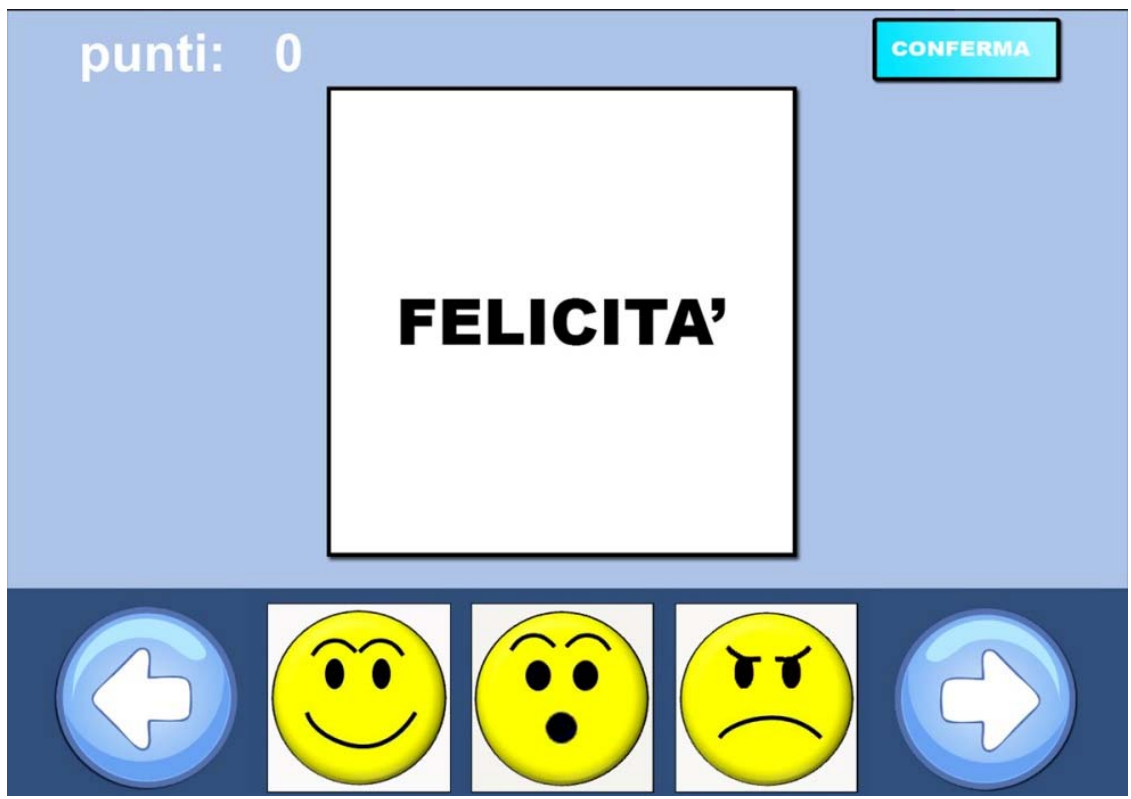

Fig. 5

In relation to the tasks of the second area, 'beliefs and false beliefs', the activities designed are related to simple perspective taking (Figure 6), to complex perspective taking (Figure 7), and to false beliefs (Figure 8).

The first two tasks in the area of 'beliefs and false beliefs' of the programme of Howlin are about the perspectivetaking skill. Literature, indeed, has showed that this skill plays a key role in the development of social skills (Berthoz, 2011, Cohen, 2004). With regards to the first two activities, these are aimed at fostering the acquisition of the principle outlined by Howlin (Hadwin, 2014) that 'seeing leads to knowledge'.

The simple perspective-taking task (Figure 6) is aimed at promoting the acquisition of the concept that objects observed by people located in several positions can see different things. Two faces of the same card are shown, each 


\section{Educational technology for inclusion: Design of an educational software for individuals with autism spectrum disorders \\ Di Tore, Sibilio}

side having a different drawing. At this point 'Sally', the main avatar in the game, places the card in front of her with only one of the faces visible to the user and asks what she can see and what the user can see. One hundred different drawings are available for this activity, providing random combinations for the two sides of the cards. The software offers the operator the possibility to insert personalised drawings or images within the task. As to the complex perspective-taking task, the activity is meant to demonstrate how people, in relation to their position, can see the same thing differently. At this level, two sub-activities are proposed. In the first case, a 3D environment is viewed (Figure 7) from a subjective perspective. Sally, the avatar, appears opposite the user. A card with a drawing on it is introduced between Sally and the user. Subsequently, the same drawing is presented on two cards, one in the same direction as the drawing shown and one rotated at $180^{\circ}$. The user is asked to indicate which of the two can be observed from his perspective and from the avatar's perspective. Meanwhile, in the second sub-activity, the user is required to explore a 3D space from different perspectives. After the exploration phase, the user is invited to answer some questions related to perspective taking.

With regards to the third activity related to false beliefs, the software presents a small animation (at present, a 3D version of the Sally and Anne experiment) and requires the user to determine the type of expression and emotion that the events presented by the protagonist will cause as a reaction. The user has three bars that manipulate the expression of the eyes, eyebrows and mouth (Figure 8). Through the combination of these parameters (also presented numerically in order to facilitate schematising), the user may create different expressions. The aim of this activity is that of promoting the creation of a link between the situation presented in the 3D animation and the emotion felt by the character in the story. The user is therefore asked to put the notions acquired in the previous sessions into practice with the scope of codifying the expressions felt by the character through the manipulation of the facial features of the avatar. Different stories are available in this activity, which gradually become more complex from one level to another. Following the narrative scheme presented in Howlin's programme, the game initially provides simple situations to which the user needs to associate an expression by manipulating the facial features. Successively, other elements are included such as the avatar's opinions, beliefs and wishes (represented by dialogues which are part of the animation). In this way, the stories aim at the gradual acquisition of the concepts of belief and false belief.

The activities related to the third area of Howlin's programme (pretend play) are still in the initial phases. For each activity designed, a reporting section aimed to facilitate monitoring of the progress of the user is also being developed. In particular, the parameters which the software should be able to register are in the study phase. At present, for each activity the software records the number of successes, mistakes and times. Moreover, a digital guide to assist teachers and operators throughout the activities is also being compiled.

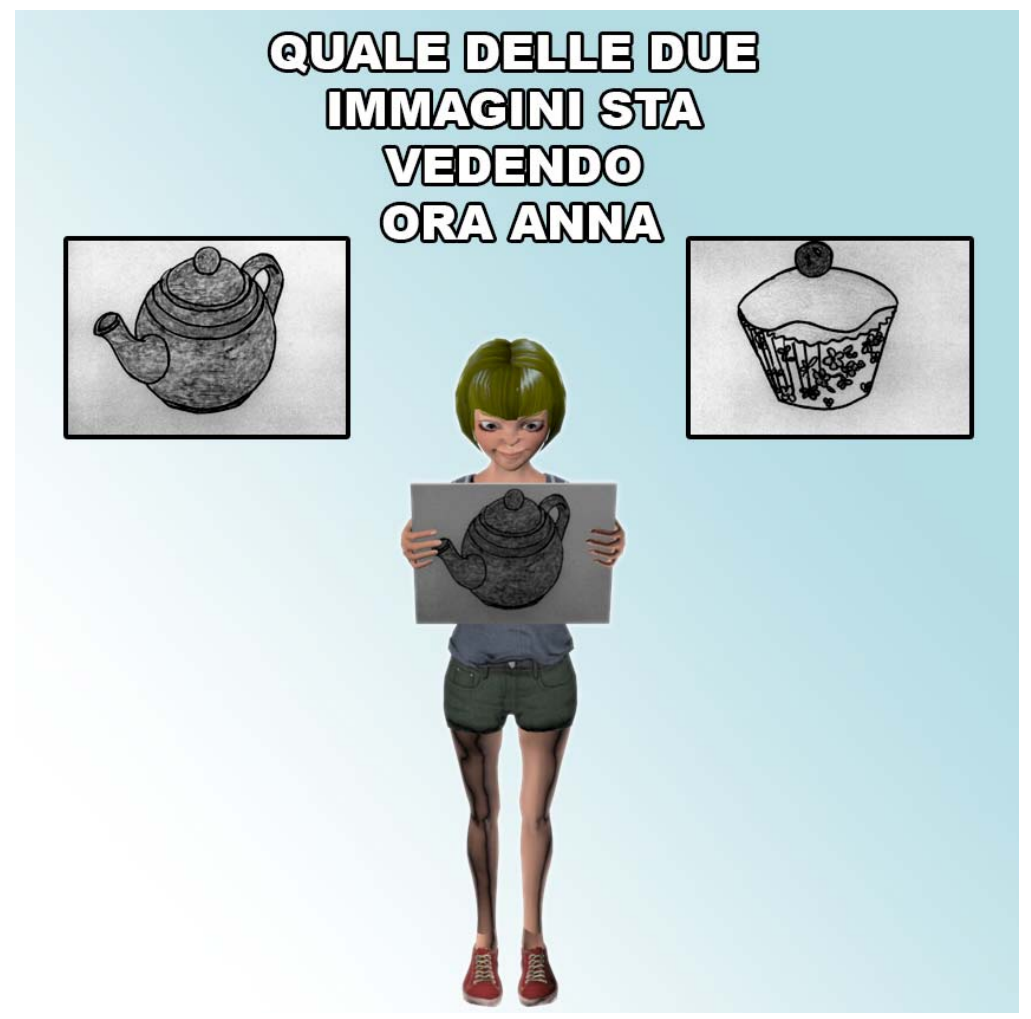

Fig. 6 


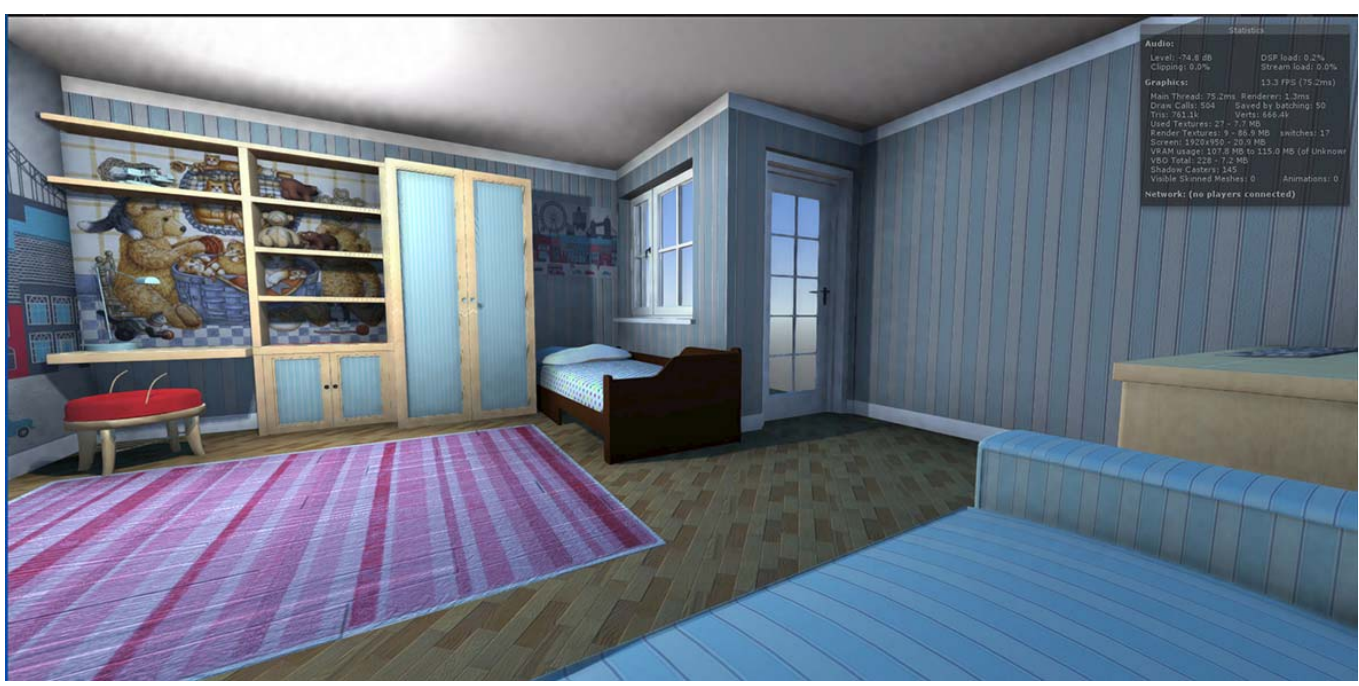

Fig. 7

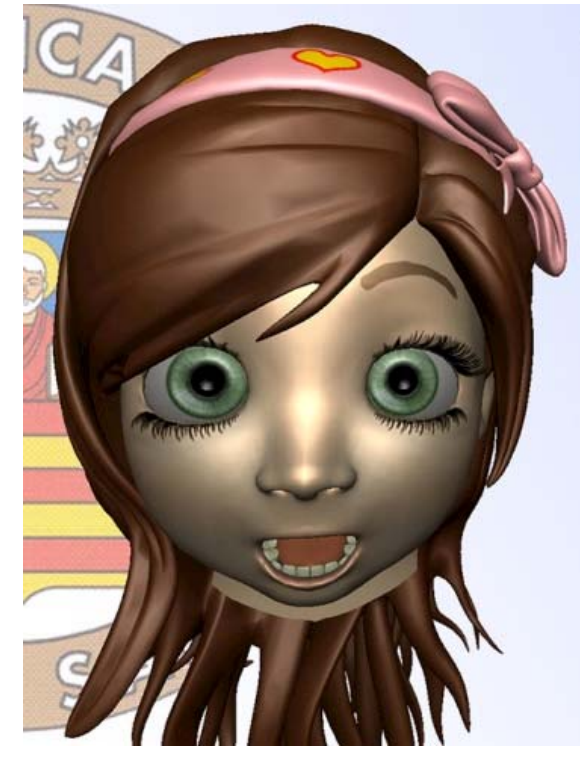

\section{Muovi le barre per configurare l'espressione che Sally dovrebbe avere}

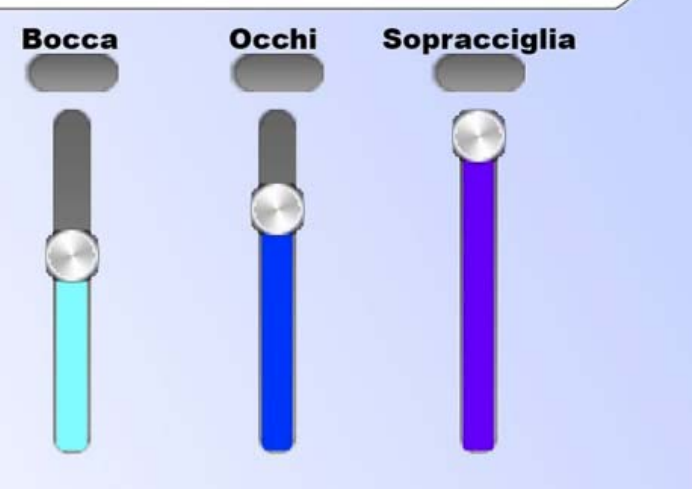

Fig. 8

\section{Conclusions}

This article describes the theoretical framework used for the design of the software. At present only some activities within the software have been developed. Future studies will be aimed at testing the individual modules and activities. The details of the tests will refer to the single abilities that each activity in the software is intended to facilitate the development.

\section{References}

Baron-Choen S. (1995). Minblindness. An Essay on Autism and Theory of Mind. Cambridge, MA: MIT Press.

Baron-Cohen S. (1988). Social and pragmatic deficits in autism: Cognitive or affective? Journal of Autism and Developmental Disorders, 18: 379-402.

Baron-Cohen S., Leslie A.M. \& Frith U. (1985). Does the autistic child have a "theory of mind"? Cognition, $21: 37-46$. Baron-Cohen, S. (1997). L'autismo e la lettura della mente. Astrolabio.

Baron-Cohen, S. (2009). Autism: the empathizing-systemizing (E-S) theory. Annals of the New York Academy of Sciences, 1156(1), 68-80. 
Baron-Cohen, S., \& Wheelwright, S. (2004). The empathy quotient: an investigation of adults with Asperger syndrome or high functioning autism, and normal sex differences. Journal of autism and developmental disorders, 34(2), 163175.

Baron-Cohen, S., Richler, J., Bisarya, D., Gurunathan, N., \& Wheelwright, S. (2003). The systemizing quotient: an investigation of adults with Asperger syndrome or high-functioning autism, and normal sex differences. Philosophical Transactions of the Royal Society of London B: Biological Sciences, 358(1430), 361-374.

Berthoz, A. (2011). La semplessità, Torino: Codice.

Berthoz, A. (2015). La vicarianza. Il nostro cervello creatore di mondi, Torino: Codice.

Colman A. M. (2001), A Dictionary of Psychology, Oxford: Oxford University Press.

Frith, U. (2010). L'autismo, Roma: Laterza.

Gallese V. \& Goldman A. (1998). Mirror neurons and the simulation theory of mind-reading. Trends in Cognitive Sciences, 12: 493-501.

Gallese V., Keysers C. \& Rizzolatti G. (2004). A unifying view of the basis of social cognition. Trends in Cognitive Sciences, 8: 396-403.

Gallese, V., Migone, P., \& Eagle, M. N. (2006). La simulazione incarnata: i neuroni specchio, le basi neurofisiologiche dell'intersoggettività e alcune implicazioni per la psicoanalisi. Psicoterapia e scienze umane, XL, 3: 543-580.

Golan, O., Ashwin, E., Granader, Y., McClintock, S., Day, K., Leggett, V., \& Baron-Cohen, S. (2010). Enhancing emotion recognition in children with autism spectrum conditions: An intervention using animated vehicles with real emotional faces. Journal of autism and developmental disorders, 40(3), 269-279.

Grandin T. (1995). Thinking in Pictures. New York: Doubleday

Grice H. P. (1975), Logic and conversation. In R. Cole e J. Morgan, Syntax and semantics: Speech acts, New York: Academic Press.

Hadwin, J. A., P. Howlin, et al. (2014). Teaching Children with Autism to Mind-Read: The Workbook, USA: Wiley.

Rivoltella, P. C. (2014). La previsione. Neuroscienze, apprendimento, didattica, Brescia: La Scuola.

Rivoltella, P. C. and P. G. Rossi (2012). L'agire didattico. Manuale per l'insegnante, Brescia: La Scuola.

Rossi, P. G. (2011). Didattica enattiva. Complessità, teorie dell'azione, professionalità docente: Complessità, teorie dell'azione, professionalità docente, Milano: Franco Angeli Edizioni.

Sibilio, M. (2014). La didattica semplessa, Napoli: Liguori. 